\title{
Editorial Revista Chilena de Antropología
}

Desde su primer número en 1978, la Revista Chilena de Antropología ha sido una publicación regular que ha tenido como principal preocupación el fomento y divulgación de la investigación antropológica chilena, manteniendo un espacio abierto para la reflexión crítica e innovación en nuestra disciplina. Los nuevos desafíos que ha impuesto la investigación científica, el sistema de publicaciones y la internacionalización de la práctica científica tuvieron repercusiones también en nuestra revista. Es por tal razón que desde el año 2010 nuestra publicación edita dos números al año y declara como objetivo difundir y discutir la investigación en las diferentes ramas de la Antropología a una escala más amplia, que cubre Latinoamérica y el Caribe.

Esta situación ha llevado no sólo a que en el último tiempo hayamos publicado una cantidad importante de contribuciones de autores de diferentes nacionalidades e instituciones, sino que también el número de papers recepcionados para ser considerados en el proceso de evaluación haya aumentado progresivamente. Esto ha repercutido en que nuestra tasa de aprobación de artículos se mueva entre un 35 a $45 \%$, y en que la revista requiere espacios más amplios en su interior para poder alojar y publicar un mayor número de las contribuciones recibidas y aceptadas, acortando de esta manera los tiempos de todo el proceso editorial. Es por tal razón que la revista ha sido rediseñada a un tamaño más grande y con un formato de dos columnas, permitiéndonos dar espacio a un mayor número de artículos, sin que ello signifique una reducción en la calidad de los artículos a publicar.

Inaguramos este nuevo formato de la revista con este volumen, y el siguiente, dedicados por completo a la publicación de trabajos presentados en el III Encuentro Latinoamericano de Zooarqueología, organizado por nuestro Departamento el año 2012. Todos estos trabajos han pasado por un proceso de evaluación por pares externos, así como cualquier otro artículo enviado a nuestra revista, reflejando este conjunto de papers el espíritu de nuestro posicionamiento: una mirada internacional sobre problemas propios de la disciplina antropológica, ocupando a nuestro país como espacio desde el cual entablar tal discusión. 